\title{
Application of Action-oriented Teaching Mode in Automobile Course Teaching in Higher Vocational Colleges
}

\author{
Dai Shixun \\ Department of automotive engineering, Shandong Laber Vocational and Technical College, Jinan, Shandong, \\ 250000, China \\ daishixun@126.com
}

Keywords: Action-oriented; teaching mode; higher vocational education; automobile course; teaching application.

\begin{abstract}
In recent years, with the development of economy and society, people's living standard has been generally improved, and higher requirements have been put forward in transportation. Various types of automobiles are constantly appearing in the scope of people's use. The increase of automobile production and use makes the work of automobile maintenance more and more important. Higher vocational colleges bear a very important responsibility in the training of technical personnel of automobile maintenance specialty. A large number of practices have proved that if higher vocational colleges can effectively carry out the teaching of automobile courses, they can mobilize the enthusiasm of students to participate in the teaching of courses, and help students to learn various automobile maintenance well. The knowledge of repairing and so on will be very helpful for students to do a good job in automobile repairing after graduation. In the teaching of automobile course in Higher Vocational colleges, many places have explored the "55533" action-oriented teaching mode. This mode fully applies modern educational technology and adopts the "teaching-doing" integration on-the-spot teaching, which greatly stimulates the initiative of students to participate in learning, and has a comprehensive and in-depth understanding of students and learning steam. Knowledge of cars is of great help.
\end{abstract}

\section{Introduction}

Since 2000, under the leadership of the Party and the government, our country's economy has made great progress, people's purchasing power in automobile has been constantly improving, automobile has become a common consumer in people's life, the demand for automobile maintenance and other aspects of society has been increasing, if you can skillfully handle it Grasp the technical knowledge of automobile maintenance, maintenance and other aspects, for higher vocational students in the future employment life has a very good role, some can be seen, for higher vocational education stage of automobile course teaching must be paid enough attention. In recent years, China's higher vocational colleges have made great progress, automotive specialty is one of the important teaching projects, the traditional teaching, one-sided dependence on the theoretical explanation of teachers, for many of the automotive knowledge, students appear to understand, it is difficult to have a thorough understanding. A large number of teaching practices have proved that if we can deepen the "55533" action-oriented teaching model in the current automobile curriculum in Higher Vocational colleges, it will be very helpful to improve the classroom teaching effect and enhance students'ability of self-learning and hands-on thinking.

\section{The difference between action oriented teaching mode and traditional teaching method}

In literal sense, action orientation is also called practice orientation or behavior orientation. Since the 1980s, the research on this kind of action-oriented teaching has been increasing and deepening, which has made a lot of achievements both in theoretical research and practical teaching. 
Action-oriented teaching model has been paid attention to by vocational education colleges all over the world. It is a brand-new teaching model. This teaching model breaks through the traditional teaching characteristics in the closed campus environment, no longer focusing on the theoretical level, but closely linking the actual teaching with the actual production needs of society and enterprises. In combination, vocational colleges need to organize their own teaching according to the production and operation needs of enterprises, which makes the former professional discipline system replaced by professional behavior system. This makes the connotation of vocational education become more and more rich, in the past, vocational education is more emphasis on theoretical learning, the current goal of vocational education is a comprehensive range of theoretical knowledge, professional skills and key abilities.

A large number of practices have proved that in the action-oriented teaching mode, students in higher vocational colleges not only learn a lot of theoretical knowledge, which is closely linked with the actual development of the current social automobile industry, for the actual operation of students has a very strong guiding role, students can also from the forefront of the level. Grasp yourself. At the same time, in this mode of teaching, higher vocational colleges should strive to enhance students'professional skills in automobile, because the initial teaching activities are around the needs of social and enterprise development, schools have built and improved a variety of automobile operation simulation sites, students actually participate in automobile maintenance and so on. With the increasing opportunities, there is a good combination of theoretical learning and practical operation in the classroom. In addition, the action-oriented teaching mode has greatly improved the comprehensive ability of students in Higher Vocational colleges, and the speed of their social integration into enterprises has increased rapidly. This not only reduces the cost of enterprise personnel training, but also makes the students in Higher Vocational Colleges better recognized by social enterprises. Because of the obvious advantages of Action-oriented Teaching mode, it has been unanimously recognized by the special topics of vocational education and enterprises all over the world. Compared with the traditional higher vocational automobile course, the action-oriented teaching mode has made a great breakthrough, but it is not completely out of touch with the traditional teaching mode. There are also many places that can be combined organically between the two, so as to provide more and better situations for students. The action-oriented teaching model is a very important part in the whole educational sports, but it can not replace all the teaching links. Therefore, in the practice of the actual teaching model, we need to consider all the links and grasp all the influencing factors comprehensively, so as to ensure the basis of the action-oriented teaching model. This effect.

\section{The construction of action oriented teaching mode of "55533" of professional courses in Higher Vocational Colleges}

Background analysis. Since the beginning of the 21st century, whether in the world or in our country, the importance of professional and technical personnel in higher vocational colleges has been greatly enhanced. Especially in our country, the Party and the government have issued a series of policies and measures to promote the construction and development of Higher Vocational colleges, which makes the construction of Higher Vocational colleges in our country. Establishment and development entered a golden era. In the past, higher vocational colleges tended to cultivate theoretical talents. Although this kind of talents have profound theoretical attainments, in practical theoretical study, there is often a disconnect between talent cultivation and the actual needs of social enterprises, which requires the cultivation of high-skilled applied talents. The cultivation of self-cultivation and quality should be integrated into the teaching and practical study of the course, and the combination of theoretical study and skill training with the actual needs should be carried out. The "55533" action-oriented teaching mode is based on the teaching reform of the course "Application of Automobile Machinery Foundation Technology" in the automobile application specialty of Higher Vocational colleges.

"Application of Automobile Mechanical Foundation Technology" is a very basic technical course, 
fully in line with the actual needs of the current higher vocational personnel training, not only has advanced automotive theory knowledge, but also a large number of practical operation, the entire technical course is dedicated to the training of high-skilled professional and technical personnel. In the past, there were a lot of teaching contents about automobile courses, but the contents of these courses are more the embodiment of theoretical explanation. In the whole teaching process, the emphasis is on the analysis of the theoretical basis of various automobile knowledge, and the actual teaching tools are very single, mainly the teacher speaking on the platform, or through. Chalk writing on the blackboard, this teaching model helps teachers to complete the relevant teaching tasks according to their own ideas, but from the actual learning of students, there are obvious shortcomings, students in this boring learning environment, for the teacher to explain some of the complex content is not in-depth, it is difficult for students It is difficult to grasp the content of courses and achieve the purpose of high-quality skills training. From about 2010, the reform of education and teaching in higher vocational colleges has been deepened, and the mechanical basic courses which occupied a considerable proportion in the teaching of automotive courses in higher vocational colleges have been shrinking. It is difficult to meet the needs of high-level and high-level cultivation of students by overemphasizing the traditional teaching mode of theory. The traditional teaching mode of automobile course in higher vocational colleges is reformed. Based on such social development background, many places insist on putting students at the teaching center, devoting themselves to the deepening of practical teaching, taking project guidance as the core, constantly promoting the optimization and perfection of teaching design, and cultivating the basic mechanical maintenance ability of students majoring in automobile in Higher Vocational Colleges Force as the ultimate goal, the composition of the car and transmission line as the main line, according to the overall structure of automotive machinery analysis, automotive power plant mechanism analysis and application, automotive parts of traditional device effectiveness certification and analysis of the task design of new teaching units.

The basic framework of "55533" action oriented teaching mode. This kind of Action-oriented Teaching mode, mainly through the design and development, is to enhance the basic ability of students, combined with the actual teaching needs of Higher Vocational colleges, according to the actual needs of enterprises to determine the basic teaching tasks, starting from the structural understanding, and strive to combine classroom theory and practical skills training, based on this. Knowledge design and implementation of the "55533" action oriented teaching. This action-oriented teaching model fully considers the basic characteristics of the current automotive specialty, accurately grasps the basic objectives of the automotive course teaching, starting from the automotive structure, decomposes five tasks, divides five learning situations with five basic teaching links, and contains three parts in the whole process. The commonly used teaching methods have adopted 3 assessment methods for the whole teaching.

\section{Practical application analysis of the "55533" action oriented teaching mode of the current automobile course in Higher Vocational Colleges}

In the whole teaching practice, highlight the dominant position of students in Higher Vocational colleges, regardless of the choice of teaching content or the design of classroom teaching links, we should fully consider the actual acceptance needs of students and ability training needs. In teaching, we should make full use of all kinds of automobile teaching and training bases that have been built in Higher Vocational colleges, organize students to come to various training environments to recognize the whole structure of automobile from small details, and train repeatedly around some necessary skills, aiming at some of them. Complicated learning tasks, teachers need to make full use of integrated classrooms, automotive training rooms and other anatomical teaching, so that teachers can explain the content and the actual operation more closely combined, students can not place, teachers can carry out on-site operation. This kind of teaching completely breaks the past classroom-based teaching model, so that students have more opportunities to do their own thinking, in such a scenario, with the teacher's guidance at any time, students'own professional and technical ability and 
comprehensive level have been significantly improved.

Extracurricular teaching is a very important part in the teaching of automobile course in Higher Vocational colleges. It plays a very important role in extending classroom theory teaching and further enriching students'professional cognition. It is a very complicated system. There are many links in practice, including various kinds of concrete links. Practical learning of virtual type platform, consulting of various types of books and materials, communication of complex technology, around these contents can be in-depth study of teaching content not understood in the classroom, this process can be a good training of students'autonomous inquiry ability, to stimulate their interest in participation is also very important. Big help. Secondly, make full use of all kinds of training places. In the past, the training places were strictly controlled in time, which was not conducive to the students'need for further practice of their own skills. Therefore, these training places should ensure that students can be effectively used at all times. At the same time, these training places should also think of all kinds of training places. Skills competition is open to the public, so its practical value will be high. Thirdly, combined with the needs of the combination of production and operation of Higher Vocational Colleges and enterprises, students can be organized to observe various types of automobile production workshops, experience the manufacturing needs of different automobile production links and processes on the spot. Through on-site observation, we can find more combination of classroom theoretical learning and practical skills application. At the same time, it can also arrange students to go to the enterprise workshop for productive exercise, which is to hone the will of students, enhance the level of self-application of technology has a very strong role.

In the actual teaching of automobile course, in order to enhance students'perceptual knowledge and enable them to study independently, we should try to integrate all kinds of modern teaching methods into the action-oriented teaching model. Combining with the actual teaching needs, the project-driven teaching method is adopted in the teaching, which integrates full practical operation and emotional knowledge into the teaching of each unit to ensure that students have a comprehensive understanding and understanding of the various components of the automobile, the basic principle design and so on, so that it can be well eliminated. Understanding students' fear of difficulties. Combined with multimedia teaching technology, we should fully apply the teaching method of "virtual" + "physical objects". From the current automobile teaching practice, many of the teaching content is very complex, especially some automobile components, it seems very simple, the actual operation principle is very complex, through perceptual knowledge, students have a basic understanding of the overall structure of the automobile, but there are still many in the depths Ambiguities. Practice has proved that by introducing practical cases of automotive engineering application background and combining with multimedia teaching technology in Higher Vocational colleges, we can carry out various types of virtual display, and at the same time, we can combine the explanation of the physical demonstration of automotive structure with the case teaching method of "virtual"+ "physical object". Difficult to understand the problem, can achieve the effect of zero, students in the actual understanding has become easier.

\section{Conclusion}

In the current automobile measurable teaching in Higher Vocational colleges, the use of action-oriented teaching model can well arouse the enthusiasm of students to participate in the curriculum, but also to develop students'practical ability, which is very helpful to improve the overall classroom teaching effect, for this reason, for action-oriented teaching. The mode of learning must be highly valued and studied in depth.

\section{References}

[1] Yu Cuijuan. Analysis of the Importance of Action-oriented Teaching Model in the New Situation [J] Teaching Method, 2017, 15 (03): 17-19.

[2] Gu Nianbin. Current Automobile Course Teaching Research in Higher Vocational Colleges [J] 
Higher Vocational Colleges, 2017, 14 (03): 21-23.

[3] Dong Tonghui. Application of Action-oriented Teaching Model in Automobile Teaching in Higher Vocational Colleges [J] Automobile Teaching, 2016, 17 (07): 19-20

Dai Shixun (1984.04-), male, Han, Jinan, Shandong Province, political outlook: Party members, lecturers, master's degree, mainly engaged in automobile Education Research. 